\title{
Follow-up Reality for Breast Cancer Patients - Standardised Survey of Patients and Physicians and Analysis of Treatment Data
}

\author{
Nachsorgerealität von Brustkrebspatientinnen - standardisierte Befragung \\ von Patientinnen und Ärzten sowie Analyse der Behandlungsdaten
}

\author{
Authors \\ D. Wey ${ }^{2}$, R. Weide ${ }^{3}$ \\ Affiliations \\ ${ }^{1}$ Institut für Versorgungsforschung in der Onkologie, Koblenz
2 Brustzentrum im Marienhof, Katholisches Klinikum Koblenz-Montabaur, Koblenz
${ }_{3}$ Praxisklinik für Hämatologie und Onkologie, Koblenz
}

S. Feiten ${ }^{1}$, J. Dünnebacke ${ }^{2}$, V. Friesenhahn ${ }^{1}$, J. Heymanns ${ }^{3}$, H. Köppler ${ }^{3}$, R. Meister ${ }^{1}$, J. Thomalla ${ }^{3}$, C. van Roye ${ }^{3}$,

\section{Key words \\ - follow-up \\ - breast cancer \\ - survey \\ - treatment data \\ - guidelines}

Schlüsselwörter

- Nachsorge

- Brustkrebs

- Befragung

- Behandlungsdaten

- Leitlinien

Deutsche Version unter: http://dx.doi.org/ $10.1055 / \mathrm{s}-0042-106210$

\begin{abstract}
received $\quad 3.3 .2016$ revised $\quad 8.4 .2016$ accepted $\quad 8.4 .2016$
\end{abstract}

\section{Bibliography}

DOI http://dx.doi.org/ 10.1055/s-0042-106210

Geburtsh Frauenheilk 2016; 76: 557-563 @ Georg Thieme

Verlag KG Stuttgart · New York . ISSN 0016-5751

\section{Correspondence}

\section{Stefan Feiten}

Institut für Versorgungs-

forschung in der Onkologie

Neversstraße 5

56068 Koblenz

s.feiten@invo-koblenz.de

\section{Abstract}

\section{$\nabla$}

Introduction: Currently, about 360000 breast cancer patients who could, after completion of their primary therapy, take advantage of followup options are living in Germany. Up to now very little is known about the extent to which the available options are used and as to how the follow-up reality is experienced and evaluated. Thus, an explorative examination among the patients and their physicians was undertaken.

Patients and Methods: All patients who underwent surgery in a certified breast centre between 2007 and 2013 received a standardised questionnaire; at the same time the physicians responsible for the follow-up were invited to answer a standardised questionnaire.

Results: 920 patients (response rate: $61 \%$ ) with a median age of 65 years (32-95) could be analysed. 99\% of the participants stated that they regularly attended follow-ups. The personal contact with the physician (mean value: 4.4 ) and the reassurance that the cancer disease had not recurred (mean value: 4.5 ) were described on a scale of 0 to 5 to be two of the most important factors of the follow-up. Deficits were expressed with regard to psychosocial care (70\%) and the perception and treatment of physical complaints (55\%). In addition, 105 physicians returned completed questionnaires (response rate: $12 \%$ ). For asymptomatic patients the physicians performed the following examinations most frequently: anamnesis (92\%), physical examination (87\%) as well as laboratory tests (63\%) and tumour marker determinations (40\%).

Conclusion: On the whole it became clear that the vast majority of the patients took advantage of the follow-up options. From the patient's perspective the importance of the follow-up lies in contact to the physician and the comforting assurance that the breast cancer has not relapsed. Deficits are seen in the psychosocial care and the

\section{Zusammenfassung \\ $\nabla$}

Einleitung: In Deutschland leben etwa 360000 Brustkrebspatientinnen, die, nach Abschluss ihrer Primärtherapie, Nachsorgeangebote in Anspruch nehmen können. Bisher ist nur wenig darüber bekannt, inwieweit die vorhandenen Angebote genutzt werden und wie die Nachsorgerealität erlebt und beurteilt wird. Hierzu wurde eine explorative Untersuchung mit Patientinnen und Ärzten durchgeführt.

Patientinnen und Methoden: Alle Patientinnen, die zwischen 2007-2013 in einem zertifizierten Brustzentrum operiert wurden, erhielten einen standardisierten Fragebogen; gleichzeitig wurden nachsorgende Ärzte zur Beantwortung eines standardisierten Fragebogens eingeladen.

Ergebnisse: 920 Patientinnen (Response-Rate: 61\%) mit einem medianen Alter von 65 Jahren (32-95) konnten analysiert werden. 99\% der Befragten gaben an, regelmäßig zur Nachsorge zu gehen. Der persönliche Kontakt zum Arzt (Mittelwert: 4,4) und die Rückversicherung, dass die Krebserkrankung nicht rezidiviert ist (Mittelwert: 4,5 ), wurden auf einer Skala von 0 bis 5 als 2 der wichtigsten Nachsorgequalitäten beschrieben. Defizite wurden bez. der psychosozialen Betreuung (70\%) und der Wahrnehmung und Behandlung körperlicher Beschwerden (55\%) geäußert. Zusätzlich beantworteten 105 Ärzte einen Fragebogen (Response-Rate: 12\%). Bei asymptomatischen Patientinnen führten die befragten Ärzte folgende Untersuchungen am häufigsten durch: Anamnese (92\%), körperliche Untersuchung (87\%) sowie Labor (63\%) und Tumormarkerbestimmung (40\%).

Schlussfolgerung: Insgesamt wird deutlich, dass eine überwältigende Mehrheit der Patientinnen das Nachsorgeangebot nutzt. Aus der Patientenperspektive liegt die Bedeutung der Nachsorge vor allem im Arztkontakt und in der beruhigenden Rückversicherung, dass die Brustkrebs- 
perception and treatment of physical impairments. Not recommended examinations were employed by a significant proportion of the surveyed physicians. erkrankung nicht rezidiviert ist. Defizite zeigen sich in der psychosozialen Betreuung und in der Wahrnehmung und Behandlung körperlicher Beschwerden. Nicht empfohlene Untersuchungen werden von einem signifikanten Anteil der befragten Ärzte eingesetzt.

\section{Introduction}

\section{$\nabla$}

Early diagnosis and improved therapeutic options have led to better survival rates for breast cancer patients [1-5]. In Germany at present about 360000 patients are living in the phase after completed primary therapy [6-7], and take advantage of the ever increasing number of follow-up options $[2,8]$.

Under follow-up (aftercare) we mean in general the structured, regular control of asymptomatic patients after a potentially curative tumour therapy [9-10]. The 2013 revision of the guidelines of the American Society of Clinical Oncology (ASCO) and the currently valid S3 guidelines recommend for all breast cancer patients a personal consultation and physical examination at intervals of 3 to 12 months as well as an annual mammography [1112]. Routine blood tests, imaging procedures, except for mammography, and determination of tumour markers, on the other hand, are not recommended for asymptomatic patients [11-12]. From the point of view of both the patients and the physicians, the main purpose of follow-up is the early detection of local recurrences [2]. In a meta-analysis of over 5000 patients, however, it was shown that only $40 \%$ of the isolated loco-regional recurrences in asymptomatic patients were detected during routine examinations [13], this has often led to the value of follow-up being questioned [14]. Also the detection of asymptomatic distant metastases is not a priority target of follow-up since there is no evidence from randomised studies that an early palliative intervention leads to a longer survival [9,15-16]. After completion of the initial breast cancer therapy the focus lies, above all, on the recognition and adequate treatment of long-term toxicities and side effects of the therapy [8,17-19], the detection of derivatives of the primary tumour [18], support in the psychosocial field [8] and in continuous motivation to comply with the adjuvant systemic therapy regularly [12].

In the present contribution we have assessed the subjective appraisals of the afflicted patients and the responsible physicians. Our aim was to examine the follow-up situation from various perspectives and to uncover content correlations. The methodological approach was explorative, specific hypotheses were not examined.

\section{Materials and Methods}

$\nabla$

\section{Methods of the patient survey}

All breast cancer patients who were operated in a certified breast cancer centre (Breast Centre Marienhof, Koblenz) between 2007 and 2013 were identified and personally approached in writing. The letter, signed by the treating physician, explained the aims and methodological procedures of the survey and provided information on the handling of personal data. Reminders were not sent after the first letter, nor were the patients contacted personally or by telephone. A stamped and addressed envelope was provided for the patients to return the completed questionnaire at no cost to themselves. The data were entered via machine by a service provider and checked for completeness.
The scannable, standardised questionnaire was evaluated in a pre-test and its content covered the following points: adjuvant therapies received, participation in clinical trials, utilisation of follow-up options, evaluation of follow-up intervals and duration, motivation to participate in follow-up examinations, distress in connection with the follow-up appointments, wishes and suggestions about follow-up and sociodemographic characteristics.

In addition, the medical treatment parameters of all patients were extracted from the patient records and transferred to a database. In this way, the treatment data of responders and non-responders could be compared and checked for systematic selection effects.

\section{Methods of the physician survey}

Physicians from a regional database who regularly receive invitations to participate in gynaeco-oncological further training events were also contacted in writing and invited to complete a scannable questionnaire. Reminders were again not sent to this group. Participating physicians could return the completed questionnaire in anonymous form by means of the supplied stamped and addressed envelope; these data were also entered via machine.

The previously evaluated questionnaire covered the following contents: medical setting, coordination of follow-up, performed or prescribed follow-up examinations, judgement of the recommended follow-up duration and intensity as well as of the aims and content of the follow-up.

In the questionnaires, treating physicians and patients evaluated several statements on the subject of follow-up using a 6-point scale with the endpoints " 0 " "not correct at all" or, respectively, "not at all important" and " 5 " "fully correct" or, respectively "very important".

\section{Statistical considerations}

Statistical analyses were performed with the help of SPSS 19. Frequencies and statistical measures of location were calculated as were mean values for interval-scaled data and median values for ordinally scaled data.

The analyses were done almost exclusively on a descriptive level. Assessment of statistical significance was performed with the help of the $t$ test for independent samples.

A calculation of case numbers was not done on account of the explorative character of the investigation.

\section{Data protection and ethical vote}

The ethics commission of the Chamber of Medicine of Rhineland Palatinate has given its approval for this project. The patients have declared their agreement to the scientific utilisation of their pseudo-anonymised data. 


\section{Results}

$\nabla$

\section{Non-responder analysis}

$\mathrm{N}=1520$ female patients were approached, 920 returned the complete questionnaire (response rate $61 \%$ ). The non-responders were on average 66.5 years old and thus about 2 years older than the responders $(\mathrm{p}=0.002) .54 \%$ of the non-responders had undergone breast-conserving operations, in comparison to $51 \%$ of the responders.

\section{Results of the patient survey}

At the time of the survey the average age of the 920 patients was 64.4 years (standard deviation: 11.4 years). The time period between the last operation and the survey amounted to 3.7 years on average (standard deviation: 2.0 years). For $82 \%$ of the patients the systemic therapy consisted of radiotherapy, $79 \%$ received an anti-hormonal therapy, $6 \%$ a neoadjuvant and $43 \%$ adjuvant chemotherapy. At the time of the survey $58 \%$ were still under therapy, mostly anti-hormonal (94\%). $11 \%$ reported that they had participated in a clinical trial within the framework of their treatment, namely $16 \%$ of the under 60 and $7 \%$ of the over 70 year olds. The patient characteristics are presented in $\bigcirc$ Table 1.

$94 \%$ of the patients were still in the follow-up phase at the time of the survey, $5 \%$ had already finished the follow-up phase. Nine of the participants ( $1 \%$ ) had never taken part in a follow-up option: $0.3 \%$ of the under 70 and $2.3 \%$ of the over 70 year olds. Four of the 9 patients had specifically decided against the follow-up options. Gynaecologists were involved in $97 \%$ of the follow-up procedures, 65\% additionally mentioned radiologists. Oncologist (17\%) and general practitioners (16\%) on the other hand were less strongly involved. A physical examination (93\%) and mammography (90\%) constituted the basis of the follow-up, in addition sonography of the breast or, respectively, axilla (81\%) and laboratory tests (56\%) were mentioned as diagnostic procedures that had been employed at least once per patient.

The current examination interval was considered to be "perfect" by $93 \%$ of the participants. The 12 -month interval was somewhat more critically assessed in comparison with the 6- and 3-month intervals: $87 \%$ considered it to be "just right", in contrast, for $5 \%$ it was too short and for $9 \%$ too long.

The mean values of the assessed statements showed that the follow-up was considered to be important for the patient's own health (4.7) and that an unremarkable result has a comforting effect (4.5). The majority considered themselves to be optimally managed (4.4) or, respectively, well cared for (4.4) and appreci-
Table 1 Patient characteristics - sociodemographic and medical data of the participating patients.

\begin{tabular}{|c|c|}
\hline \multicolumn{2}{|l|}{ Gender } \\
\hline female & $n=920(100 \%)$ \\
\hline \multicolumn{2}{|l|}{ Age at the time of the survey } \\
\hline - mean value (standard deviation) & $\begin{array}{l}64.4 \text { years } \\
\text { ( } 11.4 \text { years) }\end{array}$ \\
\hline \multicolumn{2}{|l|}{ UICC stage } \\
\hline stage I & $\mathrm{n}=444(48 \%)$ \\
\hline - stage II & $n=329(36 \%)$ \\
\hline > stage III & $\mathrm{n}=81(9 \%)$ \\
\hline not determinable & $n=66(7 \%)$ \\
\hline \multicolumn{2}{|l|}{ Year of the last OP } \\
\hline - 2008 or earlier & $\mathrm{n}=219(24 \%)$ \\
\hline > 2009-2011 & $\mathrm{n}=366(40 \%)$ \\
\hline > 2012-2013 & $\mathrm{n}=319(35 \%)$ \\
\hline not determinable & $n=16(2 \%)$ \\
\hline \multicolumn{2}{|c|}{ Adjuvant therapies (multiple answers possible) } \\
\hline radiotherapy & $\mathrm{n}=755(82 \%)$ \\
\hline - anti-hormonal therapy & $\mathrm{n}=731(79 \%)$ \\
\hline D neoadjuvant chemotherapy & $\mathrm{n}=58(6 \%)$ \\
\hline - adjuvant chemotherapy & $\mathrm{n}=395(43 \%)$ \\
\hline \multicolumn{2}{|l|}{ Therapy at the time of the survey } \\
\hline$\checkmark$ yes & $\mathrm{n}=502(58 \%)$ \\
\hline no & $\mathrm{n}=371(42 \%)$ \\
\hline \multicolumn{2}{|c|}{ Participation in clinical trials according to subgroup } \\
\hline total $(n=876)$ & $\mathrm{n}=97(11 \%)$ \\
\hline - under 60 years $(n=319)$ & $n=52(16 \%)$ \\
\hline - 60 to 70 years $(n=266)$ & $n=25(9 \%)$ \\
\hline over 70 years $(n=291)$ & $\mathrm{n}=20(7 \%)$ \\
\hline \multicolumn{2}{|l|}{ Health insurance } \\
\hline - statutory & $\mathrm{n}=720(78 \%)$ \\
\hline private & $\mathrm{n}=171(19 \%)$ \\
\hline others/not specified & $\mathrm{n}=29(3 \%)$ \\
\hline
\end{tabular}

ated the contact with their physician (4.4). The average values of the individual items are presented in 0 Table 2 . Deficits were expressed with regard to psychosocial care (70\%) and the detection and treatment of physical complaints (55\%) ( Fig. 1).

Considering all patients together, follow-up appointments were associated with a mean stress level of 2.1. The mean burden recorded with the help of a distress thermometer achieved a value of 4 . On applying the usual cut-off value of $\geq 5$ [20], $45 \%$ of the patients experienced above average stress before a follow-up appointment. Radiological examinations, in comparison to other follow-up appointments, were considered to be especially stress-

Table 2 Scaled evaluation of statements by the patients on the topic follow-up (mean values).

\begin{tabular}{|c|c|c|c|}
\hline & Mean value & Number of cases & Standard deviation \\
\hline Follow-up gives me a secure feeling of being healthy. & 4.3 & 886 & 1.13 \\
\hline For me contact with the physician is important in the follow-up. & 4.4 & 861 & 1,12 \\
\hline For me the follow-up is a troublesome burden that I must endure. & 0.8 & 781 & 1,48 \\
\hline An unremarkable follow-up result is comforting for me. & 4.5 & 857 & 1.14 \\
\hline Follow-up appointments already mean stress for me. & 2.1 & 807 & 1.88 \\
\hline I feel well cared for in the follow-up sessions. & 4.4 & 876 & 1.13 \\
\hline I feel optimally managed in the follow-up sessions. & 4.4 & 867 & 1.03 \\
\hline Follow-up is important for me and my health. & 4.7 & 876 & 0.84 \\
\hline $\begin{array}{l}\text { Mental and psychological consequences of the disease are given adequate consideration } \\
\text { in the follow-up. }\end{array}$ & 2.7 & 781 & 1.86 \\
\hline
\end{tabular}

The questions on the topic follow-up were answered with the help of a 6-point scale with the endpoints "not at all correct" (0) to "fully correct" (5). 


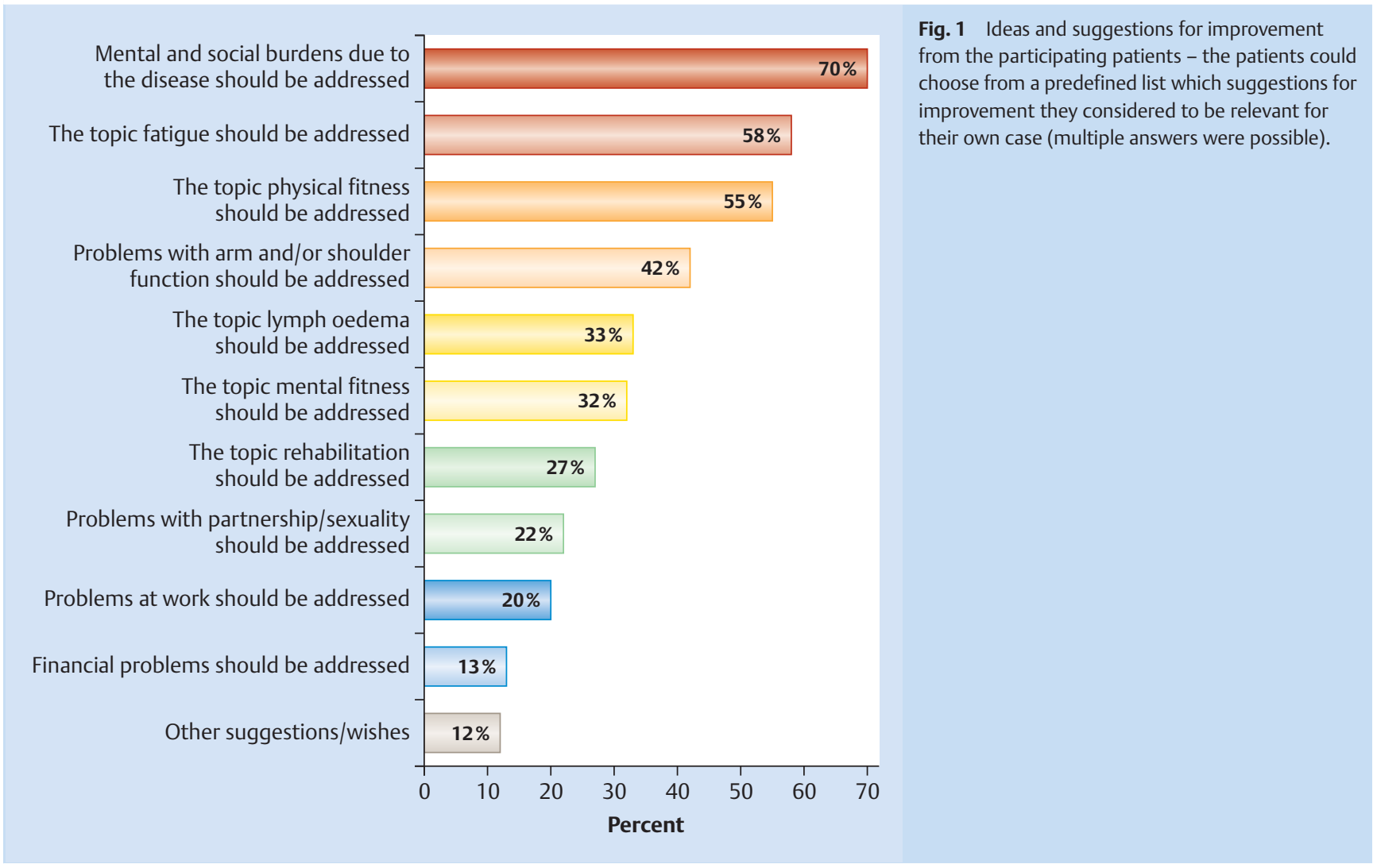

ful (median 5 vs. median 3). In these cases uncertainty or even anxiety about the examination result created distress (64\%).

\section{Results of the physician survey}

Of the 905 physicians approached, 105 returned the completed questionnaire (response rate $12 \%$ ). On average each of the participating physicians managed 10 follow-up patients per year (between 0 and 350), further characteristics of the participating physicians are given in Table 3. In $51 \%$ of the institutions there was a fixed follow-up scheme, a written follow-up plan on the other hand in merely $14 \%$. An overview of the employed examination methods is given in Table 4; anamnesis (92\%) and phys- ical examinations (87\%) were of central importance for almost all of the participating physicians. $88 \%$ considered the recommended follow-up intervals to be "exactly right", even if it was departed from in $5 \%$ of patients (median). Altogether, the participants were satisfied with the international guidelines (3.5), although the recommended duration was considered to be too short by $38 \%$. From the physician's point of view the most important aspects of follow-up are the early detection of recurrences and secondary tumours (4.8), calming the patient or reducing her anxiety (4.7), treatment of side effects of the therapy (4.5) and support in cases of psychosocial stress (4.5). The mean values for the individual items are listed in 0 Table 5 .
Table 3 Professional characteristics of the participating physicians.

\begin{tabular}{|c|c|}
\hline \multicolumn{2}{|l|}{ Specialty } \\
\hline - general medicine & $n=54(51 \%)$ \\
\hline - gynaecology & $n=31(30 \%)$ \\
\hline - internal medicine (oncology) & $\mathrm{n}=8(8 \%)$ \\
\hline - internal medicine (without oncology) & $n=6(6 \%)$ \\
\hline - radiology & $n=4(4 \%)$ \\
\hline D others & $n=2(2 \%)$ \\
\hline \multicolumn{2}{|l|}{ Main focus of work } \\
\hline practice & $n=96(92 \%)$ \\
\hline - hospital & $n=2(2 \%)$ \\
\hline - miscellaneous/mixed forms & $n=6(6 \%)$ \\
\hline \multicolumn{2}{|c|}{ Number of follow-up patients personally managed per year } \\
\hline - 3 orless & $\mathrm{n}=28(30 \%)$ \\
\hline - 4 to 10 & $\mathrm{n}=28(30 \%)$ \\
\hline - 11 to 50 & $n=23(25 \%)$ \\
\hline more than 50 & $n=13(14 \%)$ \\
\hline
\end{tabular}

Table 4 Personally performed or prescribed examinations in the course of follow-up appointments with asymptomatic patients - self reported by the participating physicians who had to make a selection from a predefined list of examination methods.

\begin{tabular}{|l|l|}
\hline Anamnesis & $\mathrm{n}=84(92 \%)$ \\
\hline Physical examination & $\mathrm{n}=79(87 \%)$ \\
\hline Laboratory test/blood chemistry & $\mathrm{n}=57(63 \%)$ \\
\hline Sonography of the breasts & $\mathrm{n}=45(49 \%)$ \\
\hline Mammography & $\mathrm{n}=41(45 \%)$ \\
\hline Sonography of the liver & $\mathrm{n}=41(45 \%)$ \\
\hline Determination of tumour markers & $\mathrm{n}=36(40 \%)$ \\
\hline Sonography of the axilla & $\mathrm{n}=35(38 \%)$ \\
\hline X-ray of the thorax & $\mathrm{n}=19(21 \%)$ \\
\hline Bone scintigraphy & $\mathrm{n}=13(14 \%)$ \\
\hline MRI & $\mathrm{n}=10(11 \%)$ \\
\hline CT & $\mathrm{n}=8(9 \%)$ \\
\hline PET/PET-CT & $\mathrm{n}=1(1 \%)$ \\
\hline Other examinations & $\mathrm{n}=7(8 \%)$ \\
\hline
\end{tabular}


Table 5 Scaled evaluation of the importance of follow-up aspects from the viewpoint of the responsible physicians (mean value).

\begin{tabular}{|c|c|c|c|}
\hline & Mean value & Number of cases & Standard deviation \\
\hline Early detection of local recurrences and secondary tumours & 4.8 & 93 & 0.72 \\
\hline Early detection of distant metastases & 4.4 & 93 & 1.07 \\
\hline Quality assurance for the primary therapy & 4.4 & 90 & 0.88 \\
\hline Calming/reducing the patients' anxiety & 4.7 & 94 & 0.53 \\
\hline Suggestions in life-style questions & 4.1 & 94 & 0.91 \\
\hline Support in smoking cessation & 3.5 & 93 & 1.32 \\
\hline Discussion and support in cases of mental/psychosocial stress & 4.5 & 94 & 0.68 \\
\hline Consultations on the topic fatigue & 4.2 & 94 & 0.84 \\
\hline Help in socio-medical/socio-legal problems & 3.9 & 94 & 1.01 \\
\hline Consultations on partnership and sexuality problems & 3.9 & 94 & 1.08 \\
\hline Detection and treatment of side effects of therapy & 4.5 & 92 & 0.69 \\
\hline $\begin{array}{l}\text { Information/support in cases of surgical interventions to improve the cosmetic results } \\
\text { of breast surgery }\end{array}$ & 3.8 & 94 & 1.13 \\
\hline Recognition of family risks and, if necessary, proposal of prevention options & 4.1 & 92 & 0.89 \\
\hline Monitoring the compliance/adherence with adjuvant therapies & 4.0 & 91 & 0.93 \\
\hline Recognition and, if necessary, treatment of long-term toxicities of the therapy & 4.2 & 92 & 0.82 \\
\hline
\end{tabular}

The importance of the individual aspects was reported with the help of a 6-point scale with endpoints "not at all important" (0) to "very important" (5).

Table 6 Degree of agreement with statements on the topic follow-up from the viewpoint of the participating physicians (mean values).

\begin{tabular}{|c|c|c|c|}
\hline & Mean value & Number of cases & Standard deviation \\
\hline The data upon which the follow-up recommendations are based are out of date. & 2.9 & 83 & 1.22 \\
\hline The follow-up should be more individualised and risk adapted. & 3.8 & 89 & 1.11 \\
\hline There are other useful measures that are not recommended in the current guidelines. & 3.1 & 84 & 1.24 \\
\hline The majority of the patients are not satisfied with the follow-up in its present form. & 1.5 & 88 & 1.33 \\
\hline $\begin{array}{l}\text { From the medical point of view an adequate adjuvant therapy is more important than } \\
\text { the follow-up. }\end{array}$ & 2.1 & 85 & 1.42 \\
\hline Follow-up examinations are not adequately reimbursed. & 3.8 & 83 & 1.14 \\
\hline The conversation between physician and patient is the most important aspect of the follow-up. & 3.8 & 90 & 1.05 \\
\hline Patients often wish for a more intensive follow-up than that recommended in the guidelines. & 3.3 & 88 & 1.40 \\
\hline
\end{tabular}

The agreement with statements on the topic follow-up of the individual aspects was reported with the help of a 6-point scale with endpoints "do not agree at all" (0) to "agree completely" (5).

The highest agreements from the side of the physicians were reached for the following statements: "the follow-up should be more individualised and risk adapted" (3.8), "the conversation between physician and patient is the most important aspect of the follow-up" (3.8) and "follow-up examinations are not adequately reimbursed" (3.8). An overview of the mean values is given in Table 6.

\section{Discussion}

The follow-up of breast cancer patients operates in a complex area of conflict between expectations and desires from the point of view of the patients, interdisciplinary medical activities and clear guideline recommendations whereby their medical efficacy remains uncertain [21].

The expectations of the patients with regard to the duration and frequency of follow-ups vary dramatically [22]. In a discrete choice experiment, the patients preferred follow-up intervals of 3 months [23]; in another survey one third did not want to return to the hospital at all after they had been informed just how rarely metastases were detected during routine clinical examinations [22]. In our study the great majority of the surveyed patients were satisfied with the duration and intervals of the follow-up. Merely $9 \%$ of the patients who were followed-up only once per year considered that the interval was too long. However, for 5\% it was even too short which is possibly indicative of a certain follow-up weariness. Our data support the conclusion that the heterogeneous expectations and preferences of the patients with regard to the length and intensity should be taken seriously and that personalised follow-ups would have the potential for a significant improvement in patient satisfaction [23]. In addition, the individual recurrence risk should be taken into consideration because the current follow-up intensity is not differentiated on the basis of the tumour biology [24].

Only little is known about the actual conduct of clinical experts and whether or not they act in accord with the guidelines [24]. In our survey numerous not recommended diagnostic procedures were mentioned and employed by a significant proportion of the participants. In this respect blood and/or laboratory tests (63\%), the determination of tumour markers (40\%) and sonographic examinations of the liver (45\%) are of primary interest. These results are in agreement with a current study in which the use of not recommended diagnostic procedures was frequently seen in follow-up patients; 55\% underwent a not recommended imaging procedure and $79 \%$ at least one not recommended biomarker test [25]. The results of other studies revealed that $97 \%$ of all patients underwent a physical examination and that mammography was not employed as frequently as is recommended [26-27]. In numerous studies reported in the literature 
it is consistently seen that the actual use of mammography is too low over the entire study period $[18,28]$ and is offset against the routine use of not recommended examination methods [24-25, 29].

In the light of the observed over- or underuse of diagnostic methods, we can only speculate about the motivations of the patients and their physicians in the face of the available evidence from prospective studies [30-32]. Attempts at explanations from the patient's point of view are the reduced concern with regard to the risk of breast cancer, other medical needs, or a low perception of the usefulness of follow-up [18]. A general dissatisfaction with the international guidelines among the participating physicians cannot be deduced although one can certainly imagine a more individual and risk-adapted procedure. Finally, the physicians are also influenced by the expectations of their patients. In a patient survey it was mentioned that one of the most important activities of the physician was not to follow the symptom-oriented follow-up guidelines [7]. In several studies the patients also preferred a more intensive follow-up scheme [2,24,29,33] and tighter controls [34].

The needs and preferences of the patients are thus in contradiction to the available evidence concerning the efficacy of followup examinations [33]. The fact that patients believe that they have a better chance of survival through more tests and the early detection of metastases and recurrences [29], however, does mean that they have not been adequately informed of the basic aims of the follow-up [33].

In conclusion, the question therefore arises about the function and practical implementation of the follow-up options. Since the incidence of local recurrences is low, huge efforts have to be made in routine follow-up to achieve the early diagnosis of a very small number of curable local recurrences [13]. This clearly illustrates the discrepancy between the expectations of the patients and the physicians' possibilities who consider the central reassurance desired by the patients that the disease has not recurred to be unrealistic [2]. Follow-up should thus be more than solely the detection of recurrences $[21,35]$. After completion of their primary therapy and also under an adjuvant therapy patients often suffer from somatic and mental complaints, lymph oedemas, fatigue, polyneuropathies and need support in their social and professional fields [19]. The feeling of security of an active treatment and its associated supportive milieu [1] is lost and its place taken by a real anxiety of recurrence, this should be adequately addressed in a comprehensive and personalised followup.

This was also apparent in the present study because a significant proportion of the participating patients reported on deficits in psychosocial care and in the appreciation and treatment of physical complaints in the framework of the follow-up. However, for a structured further treatment and follow-up and the thus associated emotional relief on the patient side, the physicians require sufficient time that is currently not appropriately reimbursed. By means of the follow-up appointments contact with the physician is maintained so that long-term sequelae of disease and therapy can be managed adequately. Follow-up also serves for quality assurance of the primary therapy and supports the consequent continuation of adjuvant anti-HER2- and/or anti-hormonal therapies. Aims, limitations and benefits of the follow-up should be discussed comprehensively with the patients at the very beginning of the follow-up to enable the patient to make an informed decision.
The strength of the present study lies in the population of more than 900 non-selected breast cancer patients who were followed-up in quite different facilities. The coupling of objective treatment data and subjective estimations of the patients not only opens up a further perspective but also makes a non-responder analysis possible. The high response rate of $61 \%$ and the results of the non-responder analysis back up the validity and representativeness of the collected data even when the responders were on average somewhat younger than the non-responders. Against the background of a $99 \%$ participation rate in follow-up options, however, it must be critically questioned if the study population is really representative for all breast cancer patients. It is possible that primarily women who actively use the follow-up options considered themselves to be directly addressed by the survey.

Since only few studies have been concerned with the opinions of physicians on the topic follow-up [5], the evaluations of more than 100 treating physicians represent a special feature of the project. However, the low response rate of $12 \%$ provides grounds for criticism. Comparable rates of between 9 and 57\% can be found in the literature [14,24,36-39], however, these surveys were often initiated by professional organisations such as, for example, ASCO. Selection effects in the sense that first and foremost those physicians participated for whom the follow-up of breast cancer patients represents an important and practically relevant topic can thus not be discounted.

\section{Conclusions}

The great majority of patients take advantage of follow-up options. From the patient's perspective the importance of the follow-up lies above all in contact with the physician and the comforting reassurance that the breast cancer disease has not recurred. Deficits are seen in psychosocial care and the appreciation and treatment of physical complaints. Not recommended examinations are employed by a significant proportion of the physicians.

\section{Acknowledgements}

$\nabla$

This project was financially supported by "medac, Gesellschaft für klinische Spezialpräparate mbH".

\section{Conflict of Interest}

The authors declare that they have no conflicts of interest.

\section{References}

1 Stanton AL. What happens now? Psychosocial care for cancer survivors after medical treatment completion. J Clin Oncol 2012; 30: 1215-1220

2 Kwast AB, Drossaert CH, Siesling S; follow-up working group. Breast cancer follow-up: from the perspective of health professionals and patients. Eur J Cancer Care (Engl) 2013; 22: 754-764

3 Hayes DF. Clinical practice. Follow-up of patients with early breast cancer. N Engl J Med 2007; 356: 2505-2513

4 Mandelblatt JS, Lawrence WF, Cullen J et al. Patterns of care in earlystage breast cancer survivors in the first year after cessation of active treatment. J Clin Oncol 2006; 24: 77-84

5 van Hezewijk M, Hille ET, Scholten AN et al. Professionals' opinion on follow-up in breast cancer patients; perceived purpose and influence of patients' risk factors. Eur J Surg Oncol 2011; 37: 217-224 
6 Bördlein I. Ärzte Zeitung: Medizin. Online: http://www.aerztezeitung. de/medizin/krankheiten/krebs/mamma-karzinom/article/337165/ brustkrebsnachsorge-noch-zeitgemaess-aerzte-betroffene-wollenverbessertes-screening-metastasen.html?sh $=25 \& \mathrm{~h}=502751114$; last access: 19.12 .2014

7 mamazone. Umfragen/Ergebnisse unserer Umfragen/Nachsorge-Umfrage. Online: http://www.mamazone.de/fileadmin/downloads/ Umfragen/Nachsorgeumfrage_Ergebnisse_2009.pdf; last access: 19.07.2015

8 Bessen T, Chen G, Street J et al. What sort of follow-up services would Australian breast cancer survivors prefer if we could no longer offer long-term specialist-based care? A discrete choice experiment. $\mathrm{Br}$ J Cancer 2014; 110: 859-867

9 Ochsner A, Zuber M, Viehl CT. Tumornachsorge nach potentiell kurativer Resektion eines Karzinoms. Ther Umsch 2012; 69: 49-55

10 Zuber M, Viehl CT, Güller U et al. Nachsorge-Empfehlungen für Patientinnen mit kurativ therapiertem, invasivem Mammakarzinom. Ther Umsch 2008; 65: 319-321

11 Khatcheressian JL, Hurley P, Bantug E et al. American Society of Clinical Oncology: Breast cancer follow-up and management after primary treatment: American Society of Clinical Oncology clinical practice guideline update. J Clin Oncol 2013; 31: 961-965

12 Deutsche Gesellschaft für Senologie. Publikationen/Leitlinien. Online: http://www.senologie.org/fileadmin/downloads/S3-Brustkrebsv2012-OL-Kurzversion.pdf; last access: 19.12.2014

13 de Bock GH, Bonnema J, van der Hage J et al. Effectiveness of routine visits and routine tests in detecting isolated locoregional recurrences after treatment for early-stage invasive breast cancer: a meta-analysis and systematic review. J Clin Oncol 2004; 22: 4010-4018

14 Donnelly $P$, Hiller L, Bathers $S$ et al. Questioning specialists' attitudes to breast cancer follow-up in primary care. Ann Oncol 2007; 18: 14671476

15 Henry NL, Hayes DF, Ramsey SD et al. Promoting quality and evidencebased care in early-stage breast cancer follow-up. J Natl Cancer Inst 2014; 106: dju034

16 Earle CC, Ganz PA. Cancer survivorship care: don't let the perfect be the enemy of the good. J Clin Oncol 2012; 30: 3764-3768

17 Kukar M, Watroba N, Miller A et al. Fostering coordinated survivorship care in breast cancer: who is lost to follow-up? J Cancer Surviv 2014; 8: 199-204

18 Lu W, Jansen L, Schaapveld $M$ et al. Underuse of long-term routine hospital follow-up care in patients with a history of breast cancer? BMC Cancer 2011; 11: 279

19 Feiten S, Dünnebacke J, Heymanns J et al. Breast cancer morbidity: questionnaire survey of patients on the long term effects of disease and adjuvant therapy. Dtsch Arztebl Int 2014; 111: 537-544

20 Mehnert A, Lehmann C, Koch U. Distress Thermometer. In: Herschbach P, Weis J, Hrsg. Screeningverfahren in der Psychoonkologie. Testinstrumente zur Identifikation betreuungsbedürftiger Krebspatienten. Eine Empfehlung der PSO für die psychoonkologische Behandlungspraxis. 2. Aufl. Berlin: DKG; 2010: 14-18

21 Chopra I, Chopra A. Follow-up care for breast cancer survivors: improving patient outcomes. Patient Relat Outcome Meas 2014; 5: 71-85
22 Montgomery DA, Krupa K, Wilson C et al. Patients' expectations for follow-up in breast cancer-a preliminary, questionnaire-based study. Breast 2008; 17: 347-352

23 Kimman ML, Dellaert BG, Boersma LJ et al. Follow-up after treatment for breast cancer: one strategy fits all? An investigation of patient preferences using a discrete choice experiment. Acta Oncol 2010; 49: 328337

24 Margenthaler JA, Allam E, Chen L et al. Surveillance of patients with breast cancer after curative-intent primary treatment: current practice patterns. J Oncol Pract 2012; 8: 79-83

25 Hahn EE, Hays RD, Kahn KL et al. Use of imaging and biomarker tests for posttreatment care of early-stage breast cancer survivors. Cancer 2013; 119: 4316-4324

26 Grandjean I, Kwast AB, de Vries $H$ et al. Evaluation of the adherence to follow-up care guidelines for women with breast cancer. Eur J Oncol Nurs 2012; 16: 281-285

27 Schapira MM, McAuliffe TL, Nattinger AB. Underutilization of mammography in older breast cancer survivors. Med Care 2000; 38: 281-289

28 Grunfeld E, Hodgson DC, Del Giudice ME et al. Population-based longitudinal study of follow-up care for breast cancer survivors. J Oncol Pract 2010; 6: 174-181

29 Schmidt S. Aktuelle Nachsorge beim Mammakarzinom: Ergebnisse einer Umfrage im Großraum München. München: LMU, Dissertation; 2013

30 Impact of follow-up testing on survival and health-related quality of life in breast cancer patients. A multicenter randomized controlled trial. The GIVIO Investigators. JAMA 1994; 271: 1587-1592

31 Rosselli Del Turco M, Palli D, Cariddi A et al. Intensive diagnostic followup after treatment of primary breast cancer. A randomized trial. National Research Council Project on Breast Cancer follow-up. JAMA 1994; 271: 1593-1597

32 Bornhak S, Heidemann E, Meisner C et al. Symptom-oriented follow-up of early breast cancer compared to intensive surveillance. Results of a prospective multicentre study: update and 10 -year overall survival. Dtsch Med Wochenschr 2012; 137: 2142-2148

33 de Bock GH, Bonnema J, Zwaan RE et al. Patient's needs and preferences in routine follow-up after treatment for breast cancer. Br J Cancer 2004; 90: 1144-1150

34 mamazone. Umfragen/Ergebnisse unserer Umfragen. Online: http:// www.mamazone.de/fileadmin/downloads/Umfragen/2012/ Report_UmfrageMitUndNachBrustkrebs.pdf; last access: 19.12.2014

35 Bördlein I. Patienten nach Krebstherapie: Ziel ist, mehr Rezidive zu verhindern. Dtsch Arztebl 2014; 111: A-1942/B-1658/C-1590

36 Paradiso A, Nitti P, Frezza P et al. A survey in Puglia: the attitudes and opinions of specialists, general physicians and patients on follow-up practice. G.S.Bio.Ca.M. Ann Oncol 1995; 6 (Suppl. 2): 53-56

37 Tomiak EM, Diverty B, Verma $S$ et al. Follow-up practices for patients with early stage breast cancer: a survey of Canadian oncologists. Cancer Prev Control 1998; 2: 63-71

38 Aitken C, Power R, Dwyer R. A very low response rate in an on-line survey of medical practitioners. Aust N Z J Public Health 2008; 32: 288289

39 Stark ME, Crowe JP jr. Breast cancer evaluation and follow-up: a survey of The Ohio Chapter of The American College of Surgeons. Am Surg 1996; 62: 458-460 